\title{
Journal on Drug Analysis
}

DOI: $10.1134 / \mathrm{S} 1061934811100224$

In 2009, Wiley \& Sons began publishing the journal Drug Testing and Analysis. The editor-in-chief is Professor Mario Thevis from the German Sports University in Cologne (m.thevis@biochem.dshs.koeln.de). The journal focuses largely on the antidoping control of athletes and application of present-day analytical methods to study drugs and many other problems. The journal is published in electronic (12 issues) and paper (6 issues) versions.

Details can be found at http://www.drugtestinganalysis.com. 